\title{
A cross sectional study to assess sleep quality in Type 2 diabetes
}

\author{
Kumar A. ${ }^{1}$, Vanishri A. ${ }^{2}$, Singh R.S.A.K. ${ }^{3}$ \\ ${ }^{1}$ Dr.Ashok Kumar, ENT specialist, ${ }^{2}$ Dr. Vanishri Ashok, Lab Registrar, Both authors are affiliated with \\ Department of Pathology,King Fahad Hospital, Saudi Arabia, ${ }^{3}$ Dr. R.S.A. Kiran Singh, Department of \\ Pathology, Katie Medical College, Guntur, India.
}

Address for Correspondence: Dr. Ashok Kumar, ENT specialist, King Fahad Hospital, Saudi Arabia. Email; vaniashok_thanks@yahoo.co.in

\begin{abstract}
Introduction: One of the commonest metabolic diseases is Diabetes mellitus. It is estimated that around 592 million people across the world would be living with diabetes by the year 2035. Multiple studies have recognized sleep disorder a novel risk factor for diabetes via peripheral neuropathy or endocrine metabolic pathway. Objective: The present study was undertaken to assess the sleep quality in type 2 diabetic patients. Methods: Thirty cases of controlled type II diabetes mellitus and thirty non-diabetic age matched controls, including both males and females, were assessed for sleep quality. Sleep quality was assessed by Pittsburgh sleep quality index (PSQI). Results: Demographic data was not significantly different between cases and controls. Sleep quality was significantly lower in cases when compared to controls $(\mathrm{P}<0.01)$. Conclusion: We have observed decrease in the quality of sleep in patients of diabetes. We recommend further studies to explore the association for planning and developing better treatment procedures.
\end{abstract}

Key words: Diabetes, Sleep quality, Life style disorders.

\section{Introduction}

One of the commonest metabolic diseases is Diabetes mellitus. It is estimated that around 592 million people across the world would be living with diabetes by the year 2035 [1]. Presently china tops the list followed by India. Based on the previous studies it has been observed that there is a 10 fold rise in Diabetes mellitus from the year $1971-2000$ (rise is $1.2 \%$ to $12.1 \%$ ) [2,3].

A study stated that sleep disturbances are found to be very common in type 2 diabetes patients and may be due to impairment in glucose metabolism and physical distress [4]; [5]. Quality of sleep is very important to lead a healthy life; it reduces the stress and burden experienced in handling the routine personal and professional life. Many studies stated that sleep disorder is a novel risk factor in the development and occurrence of diabetes. Multiple studies have recognized sleep disorder a novel risk factor for diabetes via peripheral neuropathy or endocrine metabolic pathway [6,7] Studies stated that long-term sleep disturbances

Manuscript received: $24^{\text {th }}$ April 2017

Reviewed: $2^{\text {nd }}$ May 2017

Author Corrected; $11^{\text {th }}$ May 2017

Accepted for Publication: $18^{\text {th }}$ May 2017 that are over looked routinely may further lead to chronic conditions [8]. A study reported that one of the major reasons for the increased prevalence of sleep abnormalities is due to insulin administration. The basis of poor sleep is associated with respiratory abnormalities in-turn a symptom of diabetes [9].

\section{Aim and objectives}

The present study was undertaken to assess the sleep quality in type 2 diabetic patients.

\section{Materials and Methods}

Study design: The present study was a case control study.

Setting: the study was conducted at with King Fahad Hospital, Saudi Arabia in collaboration Katuri Medical College, Guntur, India.

Participants- Thirty cases of controlled type II diabetes mellitus and thirty non-diabetic age 


\section{Original Research Article}

matched apparently healthy controls, including both males and females, were assessed for sleep quality after obtaining written informed consent. The following criteria were used while selecting the cases.

\section{Inclusion \& exclusion criteria}

1. The individuals of controlled (i.e. fasting blood sugar level $\leq 126 \mathrm{mg} / \mathrm{dl}$ and post prandial blood sugar level $\leq 180 \mathrm{mg} / \mathrm{dl}$ ) type II diabetes mellitus.

2. Age between 40-60 years.

3. Not suffering from any major complications or diseases.

\section{Results}

Demographic data was not significantly different between cases and controls. Sleep quality was significantly lower in cases when compared to controls $(\mathrm{P}<0.01)$ (Table no 1).

Table-1: Comparison of demographic data and sleep quality among cases and controls

\begin{tabular}{|c|c|c|c|c|}
\hline Sno & Parameter & Cases & Controls & P Value \\
\hline 1 & Age (years) & $43.54 \pm 5.66$ & $44.73 \pm 5.84$ & 0.4261 \\
\hline 2 & Gender (Male: female) & $18: 12$ & $20: 10$ & \\
\hline 3 & Height & $166.77 \pm 22.45$ & $162.58 \pm 26.76$ & 0.5138 \\
\hline 4 & Weight & $72.68 \pm 16.83$ & $66.22 \pm 18.10$ & 0.1576 \\
\hline 5 & Global PSQI & $11.45 \pm 5.16$ & $8.17 \pm 1.46$ & $0.0014 * *$ \\
\hline
\end{tabular}

Data was presented as Mean $\pm \mathrm{SD} . * \mathrm{P}<0.05$ is significant, $* * \mathrm{P}<0.01$ is significant, $* * * \mathrm{P}<0.001$ is significant.

\section{Discussion}

Type 2 diabetes one of the most common prevalent chronic diseases in the world, has now become a global challenge. The incidence of diabetes both in the developed and developing countries has reached the epidemic proportions and India currently known to be the diabetic capital possessing the largest number of diabetic patients, experiencing an epidemic of type 2 diabetes. According to International Diabetic Federation (IDF) in the year 2013 reported that around 62.4 million of the Indians are diabetic $[11,12]$.

There are many complications of diabetes on health one such is the poor quality of sleep, these in turn may affect the quality of life of an individual with diabetes. Certain studies even reported that there are difficulties in initiating sleep in the subjects with diabetes when compared to healthy individuals [13]. As sleep is an important activity in refreshing the body and improving the regular activities of the person. The poor quality of sleep has greater impact on the body functions leading to reduced physical and mental activities inversely affecting the quality of life. The present study is aimed to learn the quality of sleep in subjects with Type 2 diabetes.

Our study had shown a poor sleep quality in subjects with type 2 diabetes irrespective of the genders. Similar observation was made in a study stating that longer duration of diabetes had greater impact on the quality of sleep further affecting the quality of life leading to depression and anxiety [14].

There are certain studies that had elicited the effects of poor sleep leading to stress induced diabetes [15] highlighting the inter-relationship 


\section{Original Research Article}

between sleep and diabetes and vice versa. The data retrieved regarding the sleep quality and duration of the sleep is self-reported for which we cannot directly compare our results retrieved with those of the other studies used polysomnographic measures of sleep disturbances.

Various factors like diet and snoring may also be the influencing factors for the sleep disturbances found, that could be further studied. The present study helps in educating the population to learn the importance of self-management of diabetes that will improve the sleep quality and further helps in the betterment of the quality of life.

Most of the studies stated that the modern life style, prolonged unhealthy eating habits, alcohol abuse, lack of physical activity and obesity are the most commonly reported and investigated risk factors for diabetes mellitus. During sleep there are certain changes in our systemic and cognitive functions such as reduced blood pressure this may be due to decrease in the sympathetic activity, hyper or hypoventilation, hormonal secretion and hypothermia, reduction in peripheral vascular resistance and cardiac output is also experienced [14].

During sleep melatonin and leptin are secreted, wherein melatonin is involved in sleep regulation and leptin increases the intake of carbohydrates leading to predispose obesity which may further lead to chronic degenerative disease like diabetes mellitus [15]. On the other hand sleep deprivation causes increase in cortisol levels, known to inhibit production of insulin. High cortisol levels raised due to sleep deprivation shows reduced glucose metabolism and high glucose levels.16 Poor sleep in diabetic patient affects blood glucose control and glucocorticoids production causing the insulin resistance thus, making him feel more tired than a normal individual. Diabetes with retinopathy is also well studied, the study states that diabetes with retinopathy creats an hypoxic condition leading to poor oxygen supply to the retina.

Nocturia and frequent urination are the other reasons for the poor blood glucose control occurs that might be one of the causes for sleep deprivation or poor sleep in diabetic patients $[17,18]$. Poor quality of sleep noticed in type-2 diabetic patients may further lead to other mental health complications such as mood swings, depression, anxiety and physical health complications like cardiovascular or gastrointestinal problems [18].

\section{Conclusion}

We have observed decrease in the quality of sleep in patients of diabetes. We recommend further studies to explore the association for planning and developing better treatment procedures.

Funding: Nil, Conflict of interest: Nil Permission from IRB: Yes

\section{References}

1. Guariguata L, Whiting DR, Hambleton I, Beagley J, Linnenkamp U, Shaw JE. Global estimates of diabetes prevalence for 2013 and projections for 2035. Diabetes Res Clin Pract. 2014 Feb; 103 (2):137-49. doi: 10.1016/j.diabres.2013. 11. 002. Epub 2013 Dec 1.

2. Gupta R, Misra A. Type 2 diabetes in India: Regional disparities. Br J Diabetes Vasc Dis. 2007; 7 (1): 12-6.

3. Ramachandran A, Snehalatha C. Current scenario of diabetes in India. J Diabetes. 2009 Mar; 1 (1): 18-28. doi: 10.1111/j.1753-0407.2008. 00004.x. Epub 2008 Dec 17.

4. Keinanen-Kiukaanniemi S, Ohinmaa A, Pajunpaa H, Koivukangas P: Health related quality of life in diabetic patients measured by the Nottingham Health Pro- file. Diabet Med.1996; 13: 382-388.

5. Resnick HE, Redline S, Shahar E, Gilpin A, Newman A, Walter R, Ewy GA, Howard BV, Punjabi NM; Sleep Heart Health Study. Diabetes and sleep disturbances: findings from the Sleep Heart Health Study. Diabetes Care. 2003 Mar;26 (3): 702-9.

6. Barone MT, Menna-Barreto L. Diabetes Res Clin Pract. 2011 Feb;91(2):129-37. doi: 10.1016 /j. diabres.2010.07.011.

7. Spiegel K, Knutson K, Leproult R, Tasali E, Van Cauter E. Sleep loss: a novel risk factor for insulin resistance and Type 2 diabetes. J Appl Physiol (1985). 2005 Nov;99(5):2008-19. 
8. Kawakami N, Takatsuka N, Shimizu H. Sleep disturbance and onset of type 2 diabetes. Diabetes Care. 2004 Jan;27(1):282-3.

9. Resnick HE, Redline S, Shahar E, Gilpin A, Newman A, Walter R, Ewy GA, Howard BV, Punjabi NM; Sleep Heart Health Study. Diabetes and sleep disturbances: findings from the Sleep Heart Health Study. Diabetes Care. 2003 Mar;26 (3): 702-9.

10. Buysse DJ, Reynolds CF 3rd, Monk TH, Berman SR, Kupfer DJ. The Pittsburgh Sleep Quality Index: a new instrument for psychiatric practice and research. Psychiatry Res. 1989 May; 28 (2):193-213.

11. Upadhyay RP. An overview of the burden of non-communicable diseases in India.Iran $\mathrm{J}$ Public Health. 2012;41(3):1-8. Epub 2012 Mar 31.

12. International Diabetes Federation. Diabetes atlas 5th edition. International Diabetes Federation, Brussels.2013.

13. Hayashino $\mathrm{Y}$, Fukuhara S, Suzukamo Y, Okamura T, Tanaka T, Ueshima H; HIPOP-OHP Research group. Relation between sleep quality and quantity, quality of life, and risk of developing diabetes in healthy workers in Japan: the High-risk and Population Strategy for Occupational Health
Promotion (HIPOP-OHP) Study. BMC Public Health. 2007 Jun 28;7:129.

14. Lou P, Qin Y, Zhang P, Chen P, Zhang L, Chang G, Li T, Qiao C, Zhang N. Association of sleep quality and quality of life in type 2 diabetes mellitus: a cross-sectional study in China.Diabetes Res Clin Pract. 2015 Jan;107(1):69-76. doi: 10. 1016/j. diabres. 2014. 09.060. Epub 2014 Oct 17.

15. Shankar A, Syamala S, Kalidindi S. Insufficient rest or sleep and its relation to cardiovascular disease, diabetes and obesity in a national, multiethnic sample. PLoS One. 2010 Nov 30; 5 (11): e14189. doi: 10.1371/journal. pone. 0014189.

16. Resnick HE Diabetes and sleep disturbances: findings from the Sleep Heart Health Study.Diabetes Care. 2003 Mar;26(3):702-9., Redline S, Shahar E, Gilpin A, Newman A, Walter R, Ewy GA, Howard BV, Punjabi NM; Sleep Heart Health Study.

17. Almeida GPL, Lopes HF. Síndrome metabólica e distúrbios do sono. Rev Soc Cardiol São Paulo 2004 abril; 14(3):140.

18. Geib LTC, Cataldo A Neto Neto, Wainberg R, Nunes ML. Sono e envelhecimento. Rev. Psiquiatr Bras 2003 setembro; 25(3):453-65.

\section{How to cite this article?}

Kumar A, Vanishri A, Singh R.S.A.K.A cross sectional study to assess sleep quality in Type 2 diabetes. Trop J Ophthalmol Otolaryngol.2017;2(1):6-9. doi: 10.17511/jooo.2017.i01.02. 